\title{
Online learning as a result of globalization during the pandemic Covid-19
}

\author{
Evgenia Kokhanovskaya ${ }^{1,{ }^{*}}$, Elena Smychkova $^{1}$, and Maria Chai $^{1}$ \\ ${ }^{1}$ I. M. Sechenov First Moscow State Medical University, Institute of Linguistics and Intercultural \\ Communication, str. Sadovaya-Kudrinskaya, 3, bld. 1, Moscow, 119991
}

\begin{abstract}
.
Research background: The article discusses and compares the models and characteristic features of contemporary electronic distance learning (EDL). The relevance of the use of distance technologies in education, including extreme situations like a pandemic, is justified. The main emphasis is placed on the organization of the learning process, using online technologies.

Purpose of the article: This research aims to analyze and evaluate the efficiency of working in the format of electronic distance learning (EDL), as well as to investigate into various EDL models, based on the example of teaching Russian as a foreign language at the Institute of Linguistics and Intercultural Communication of Sechenov University during the COVID-19 pandemic.

Methods: Analysis and synthesis of empirical observation. The study makes it possible to assess the pros and cons of EDL from the point of view of both students and the teaching staff. Of particular importance is the fact that the authors present not only the analysis of the learning process but, also, the examination of the EDL results.

Findings \& Value added: The data presented in the work show the demand for making a connection between EDL and the traditional form of education with a view to ensuring the continuity of the educational process and improving the quality of the content created of electronic educational resources. Thus, the integration of EDL and its combination with traditional methods made it possible to avoid economic and educational losses in the extreme context of the COVID-19 pandemic.
\end{abstract}

Keywords: COVID-19; electronic distance learning; foreign language; globalization; electronic educational space

JEL Classification: $121 ; 125 ; 126$

\section{Introduction}

The article dwells on electronic distance education (EDE). The impact of globalization on the development of this educational format with its characteristic features is analyzed. The

\footnotetext{
${ }^{*}$ Corresponding author: ekokhanovskaya@yandex.ru
} 
results of the experiment conducted by the team of authors, with a one-hundred-percent transition to EDE, are also discussed in this work.

Electronic distance education has been created as a result of scientific and technological progress, as well as the worldwide computerization of various fields of human activity. This new format has become one of the most relevant forms in modern education. Now students have access to the best educational material in any field of knowledge, successfully putting this knowledge into practice. [1]

In addition, in the field of foreign language learning, in particular Russian as a foreign language (RFL), unified standards of teaching and testing, or so-called certification levels, were worked out, which allows to unify the curriculum.

All educational institutions are currently dealing with introducing and studying EDE [2], so it is necessary to understand the correlation of the two types of education: the traditional form (the classroom format) and distance education. ("The Discussion of Communicative Language Teaching Approach in Language Classrooms") [3].

\subsection{Literature review}

Interest in online learning and its quality, as well as in the search for new educational platforms in studying foreign languages, is only growing. More questions begin to arise, with answers still inconclusive. Nevertheless, the majority of methodologists and researchers have recognized the positive effect and the intensification of the process of online learning.

In their article "Online Education: Prospects of development in Russia" [1], Zakharova N., Yudintseva A. give an explanation of why "currently, two main trends can be observed in the field of distance and online education, namely: globalization of online education and its individualization. By "globalization" the authors mean the availability and mass character of online education, and by "individualization" - the independent choice of educational platforms and teaching systems, in addition to the possibility of personal and professional growth. The authors devote their article to analyzing the market for MOOC.

The very concept of "online lesson" is studied in the work of Dyakova T. and Khvorova L., "Online lesson of Russian as a foreign language in the context of pedagogical activity digital transformation" [4], where the authors separate the concept of "online learning" from that of "distance education". They introduce the term "independent linguodidactic definition of innovative language education" (online lesson) along with an analysis of such a phenomenon as "digitalization of educational space".

Quite a number of attempts have been made to classify, measure its effectiveness and give an up-to-date assessment of online learning, with the process still continuing. The authors Nikitina G., Ternova N. note that "the solution to this problem required the application of theoretical and analytical methods, supplemented by the method of experimental teaching and by statistical methods of data processing" [2]. ("Electronic teaching aids as a means of intensifying the process of foreign language teaching ")

Back in the 90s, the vast majority of world universities faced the transition to online learning in the format of teaching a particular language, giving preference to a mixed teaching method. The mixed approach in teaching languages, combining practical lessons with online classes, has been discussed by many researchers, including Luciane V. Mello of University of Liverpool [5]), Vyazovskaya V, Danilevskaya T, Trubchaninova M. of Voronezh State University [6]). The authors of Voronezh State University gave a description of the fifteen electronic educational resources and emphasized the advantages of a student-centered approach in online learning, with focusing on the blended learning format.

Previously, the issue of quality of online learning was relatively acute, along with the need to find competent educational platforms aimed at raising the level of academic performance of students and learners (Lei Zhang of Jilin Institute of Chemical Technology 
[7], Nikitina G, Ternova N. of Tambov University [2]. Digital literacy among teachers was also a topical issue (Krajcso Z, Frimmel U. of University of Vienna [8]). Electronic platforms are analyzed by Moskalenko M, Dorozhkin E, Tolstykh O. as well. In the article "Electronic learning resources and online education technology: Issues of effectiveness evaluation" [9], they give their recommendations for improving electronic educational resources and online education technologies.

However, because of the Covid-19 pandemic, the gradual transition to online platforms (from $30-50 \%$ ) has grown into a full transition (100\%). Due to a lack of universal educational platforms and a lack of technical literacy of most teachers, educational institutions are at a stalemate and "entrepreneurial hustle" [10], being forced to urgently create new types and forms of online education. [11] A new educational platform for developing WEB applications is presented by Zhang L. in the work "Development of an information-based online foreign language teaching platform with ASP.NET" [6].

It is necessary to refer to the well-known Moodle educational system [12], which has a large number of users, as well as to such popular platforms as Coursera, edX and Udacity. In Russia, educational platforms such as Zoom and Stepik are quite popular. It is also worth noting that working on such resources contributes to the development of students' internal motivation to acquire new knowledge. This is dwelt on by a group of authors from Sechenov University (Russia): Savilova S., Kropotkina A., Kokhanovskaya E., Smychkova E., Chai M. $[13,14]$.

All the above stated authors speak about the promising development of online education in the world. However, the implementation of the technological base for active online learning in some countries is still limited on account of certain economic difficulties. Besides, many teachers and students complain about cultural resistance to online learning among the general public. The psychological and economic difficulties during the period of people's self-imposed isolation were described in the work "Impact of the COVID-19 pandemic on online home learning: an explorative study of primary schools in Indonesia" [15], by authors such as Putri R, Purwanto A, Pramono R. Along with them - article "Behavioral Strategy and the COVID-19 Disruption"[16], Nicolai J. Foss.

\section{METHODS}

From February to June 2020, we had the opportunity to do research in the new form of training, its relevance and effectiveness in the conditions of full transition to EDE. The results of students' work in electronic distance and classroom formats were then analyzed and crossreferenced.

The main goal of this research was to compare the levels of students' academic excellence in different forms of training (either traditional or electronic distance education). It was also important for the researchers to demonstrate the pros and cons of applying e-distance learning in teaching a foreign language (especially in teaching RFL). It is worth noting that the work was carried out simultaneously with the reorganization of the teaching/learning process.

First-year students of medical and dental departments were selected for the experimental study, with the two groups formed: the control group (CG) and the experimental group (EG). The control group was made up of 2019 students, and the experimental group - of 2020 students. Their academic achievements were compared based on the two disciplines: Russian as a foreign language (RFL) and Biomedical conceptual apparatus (MBCA). The students of the selected groups demonstrated the same levels of academic performance in Russian as a foreign language, as well as the same motivation to study it. Those students were in the same age range and mastered the same professional field.

Experimental research includes the ascertaining, forming and control stages. 
- Ascertaining stage. In the 2019 academic year, during the spring semester, the study of MBCA as an academic subject was carried out entirely in electronic format. At the same time, another subject (RFL) was taught full-time with EDE elements. The results of the control group of the 2019 school year were as follows (Fig. 1).

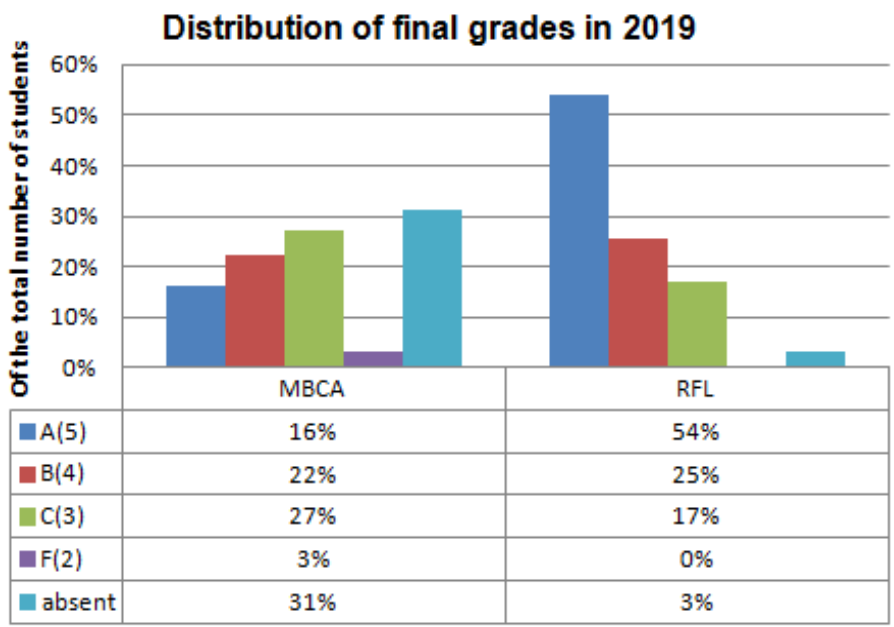

Fig. 1. Results of the spring semester 2019. CG.

Positive results are marked by grades "excellent"-A(5), "good"-B(4) and "satisfactory"$\mathrm{C}(3)$, negative results - by rating" unsatisfactory "-F(2) or failure to appear for the exam.

It is concluded that mixed learning (the classroom with the elements of electronic distance education) gives a higher result. 96.6 per cent of students achieved positive results in RFL, and 65.7 per cent of students - in MBCA. Also, "satisfactory" prevails among the positive ratings for MBCA, and "excellent" - for RFL.

- Forming stage. At the beginning of 2020, an extreme situation developed in the world: the COVID-19 pandemic. Many countries, including Russia, have taken a number of quarantine measures in response to the epidemic. In the context of universal globalization, when an international educational space was created, it became possible to change the format of education.

At this time, universities had to show their willingness to take urgent action. The Russian government instructed the Ministry of Enlightenment and the Ministry of Education and Science to organize the transfer of all educational institutions to distance learning. In the 2020 academic year, during the spring semester, the format of training was redesigned. Academic subjects such as MBPA and RFL were fully transferred to EDE, which was necessary in order to maintain the continuity of the teaching/learning process. A radical change in the forms and methods of training has led to the following risks:

- semester incompleteness

- academic debts

- tuition fee recalculating

- inability to fully control knowledge

- worsening of the quality of education.

Within a short period of time, the faculty members had to change the format of the educational process in the current situation and provide conditions for a full transition to EDE, and students had to start assimilating information at a new level. [11] 
During the COVID-19 pandemic, due to the forced interruption of lessons held in a real classroom, the following measures were taken:

1. Students were sent to the Stepik educational resource, where they were offered courses designed with the level of language proficiency in mind. The courses were developed by the teachers of Sechenov University earlier, but it is this period that students started actively joining them. As shown in the graphs (Fig.2-3), until March 15, two to three new students were registered daily, but starting from March 15, student registration was twenty to twenty five per day.

New students per day. Russian as a foreign language. Advanced level.

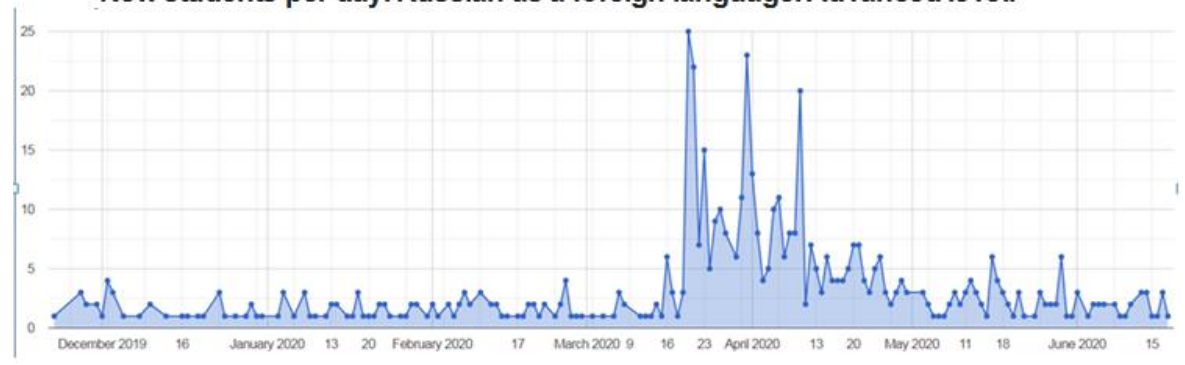

Fig. 2. The amount of those registered per day. Stepik. RFL, advanced level.

New students per day. Russian as a foreign language. For beginners

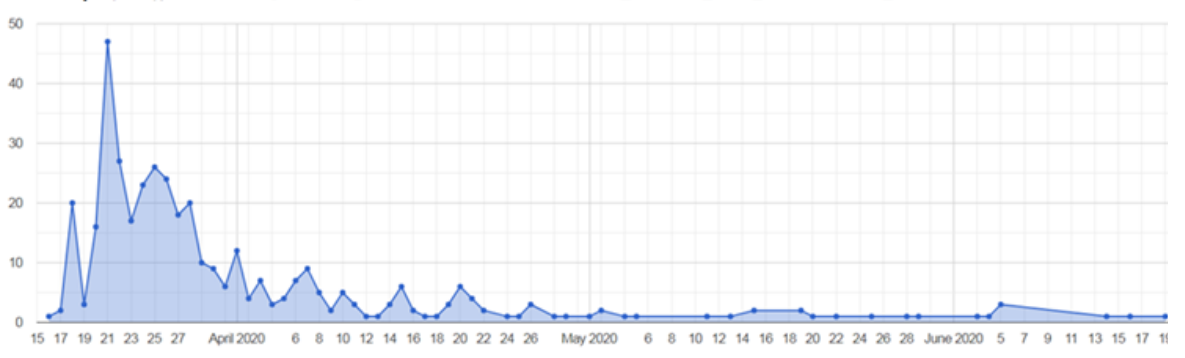

Fig. 3. The amount of those registered per day. Stepik. RFL, beginning lessons.

2. New electronic learning resources (ELRs) were created (RFL), and the existing ELRs of Sechenov University were supplemented (MBCA) on the Moodle educational platform. The courses were developed by the teachers in compliance with the University curriculum and correlated with the study and exam schedule. The use of these courses enabled students to do homework (exercises, tests, quests, etc.), as well as to pass online control tests.

It is worth noting that the tasks were formatted in different modes - training and test ones. Training modes are: when theoretical material is presented in an interactive format, where students could revise the material previously studied at video conferences or, in case of missed lessons, go through it themselves from the beginning. Test modes include an adaptive mode with a self-monitoring function and a control mode with the teacher's ability to monitor the performance of tasks and make corrections and comments.

3. Online conferences with groups of students have been launched on the ZOOM educational platform. Below is a graph of student attendance in the experimental group (Fig. 4) before and after their work in ZOOM. The decline in attendance at the beginning of the self-isolation period resulted from quarantine measures. Then active attendance at ZOOM conferences tends to return to normal. 


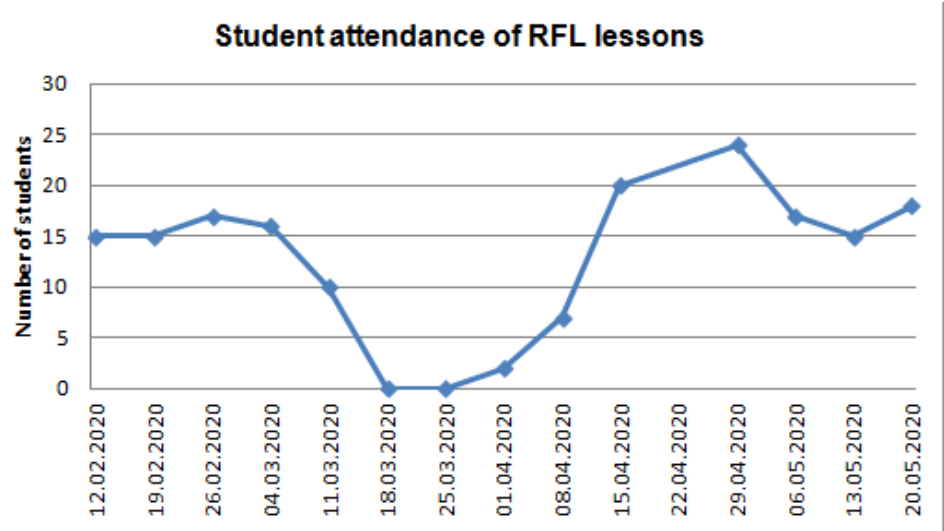

Fig. 4. Student attendance of RFL lessons before and after transition to EDE.

4. Then there was a transition of training from the Stepik platform to new electronic educational resources posted on the Unified educational portal (UEP) of Sechenov University based on the Moodle platform. The graphs (Fig. 5-6) show the number of student entries to the Unified educational portal between May and June.

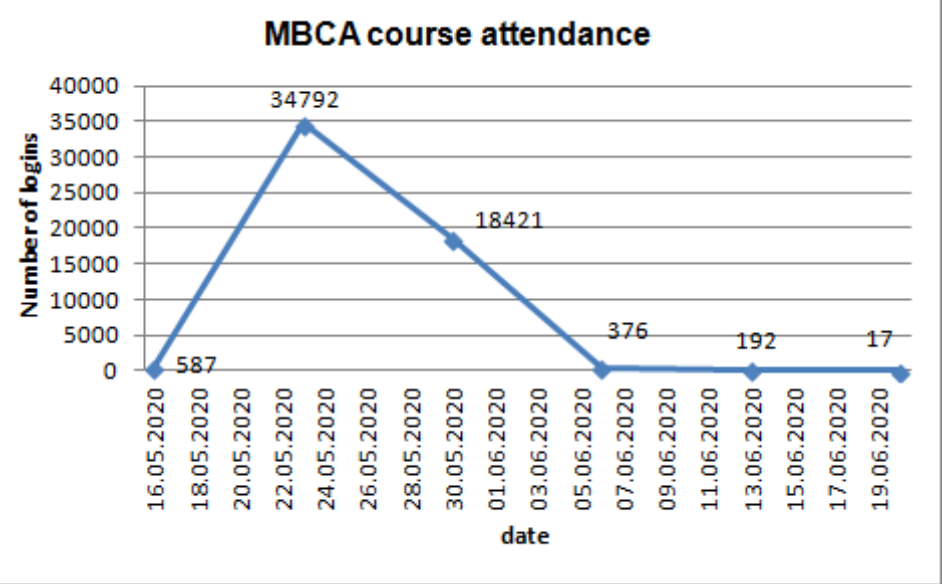

Fig.5. MBCA course attendance.

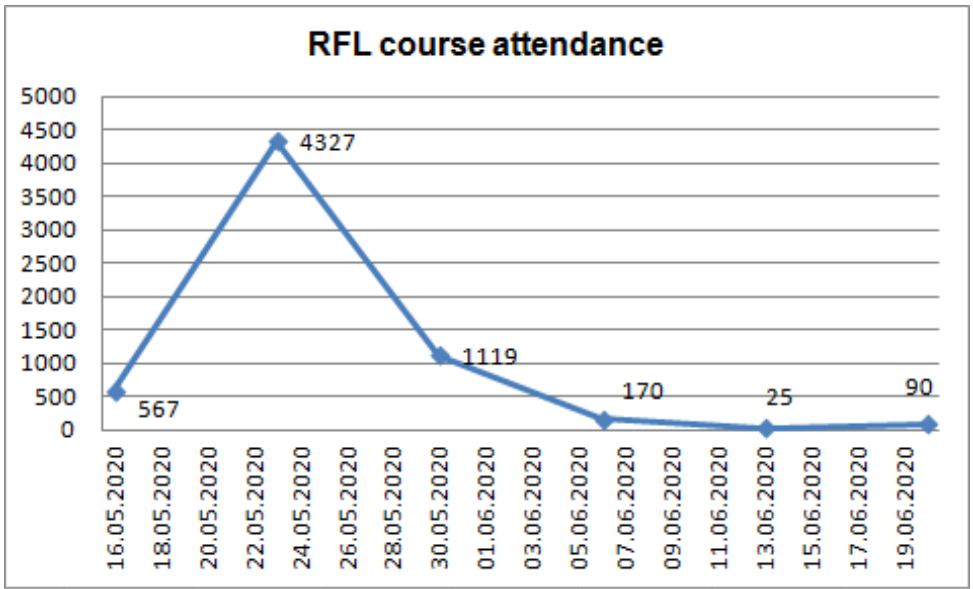


Fig.6. RFL course attendance.

An increase in the level of student activity on the UEP was due to the fact that new EERs were offered on the Moodle platform.

5. The final certification was conducted in the form of online testing and online exams, using interactive tools on the UEP, in particular, video conferences on the Big Blue Button platform.

Thus, students have been able to continue classes according to their usual schedule and then to proceed to the final certification.

This work was carried out with an experimental group. Training both in MBCA and RFL was conducted entirely online on the Stepik, Moodle, ZOOM and Big Blue Button video conferencing platforms. The study was carried out with the use of testing and observation methods.

\section{RESULTS}

At the control stage of the pilot work, the results of academic performance of students' distance learning on various online resources were compared with those achieved through training in the traditional educational form before the force majeure was linked to the pandemic.

Data on online course attendance and student activity on online resources was analyzed. The progress curve, based on checking the results of academic achievements of students in the control and experimental groups, was studied as well.

Advantages and disadvantages of various approaches to teaching RFL to students were revealed during classes of the EG. Certain advantages of using online resources include: student activity, competence development, teamwork, creativity, etc., even though this technique increases the distance between student and teacher, which leads to certain educational losses.

The results of the spring semester 2020 (Fig.7) show that the students passed the exams quite successfully. Most of them received positive ratings $(54.9 \%$ - in MBCA, $67.1 \%$ - in RFL). "Satisfactory" prevails among the positive ratings for both MBCA and RFL.

Distribution of final grades in 2020

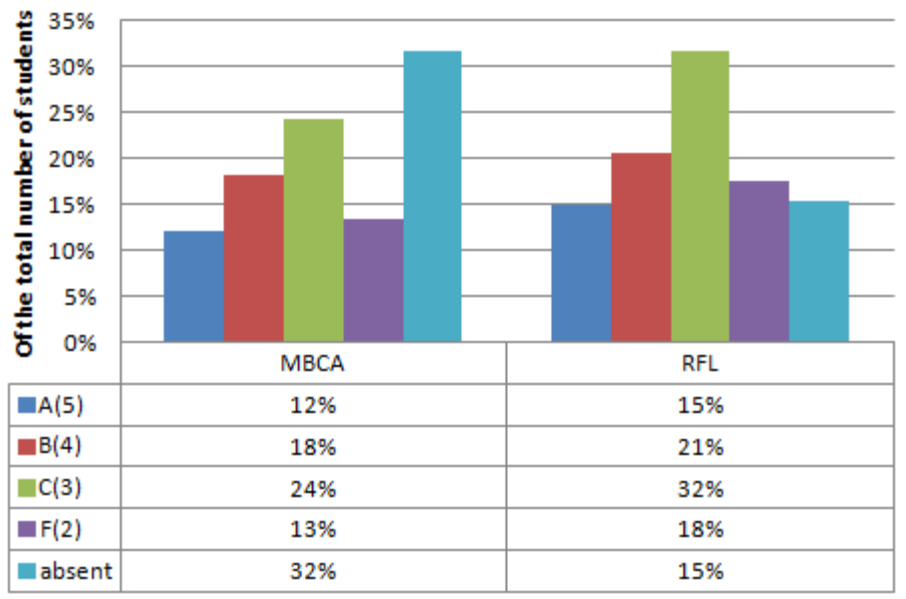

Fig.7. Final results for the spring semester 2020. EG. 
When comparing the results of the students' academic performance in the CG and the EG, we can trace the following pattern. (Fig. 8, 9). While their academic results for 20192020 slightly declined in the discipline of MBCA, they vary significantly in the discipline of RFL, as shown in the performance charts: the percentage of positive ratings in the CG is higher than that in the EG. Despite a decrease in the number of "excellent" ratings, the number of "satisfactory" ratings has increased.

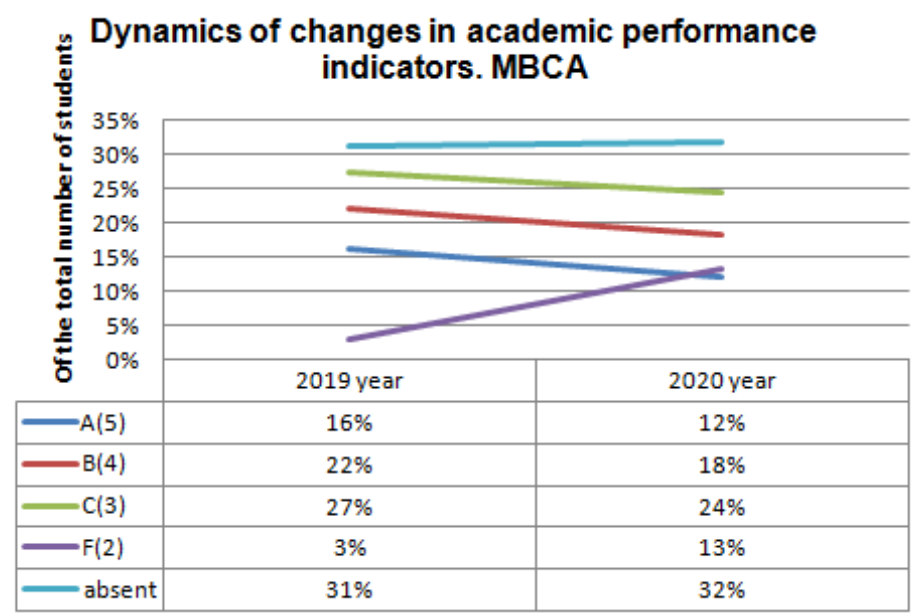

Fig.8. Results of academic performance in MBCA for 2019 compared to 2020.

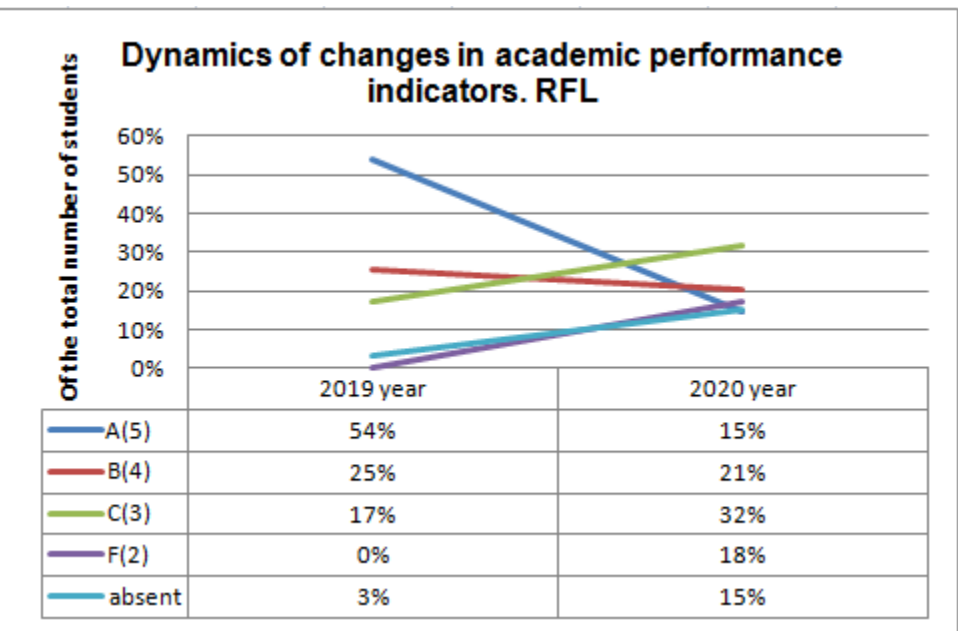

Fig. 9. Results of academic performance in RFL for 2019 compared to 2020.

We can conclude that the school year ended without significant losses due to the development of EDE. The quality of knowledge can be estimated as average. Because of the absence of a live dialogue between student and teacher, the quality component of the teaching/learning process is weakened.

\section{DISCUSSION}

Considering all of the above measures taken, it can be stated that our Institute has managed to minimize possible negative consequences of forced self-isolation. 
Based on all of the above, the following factors can be regarded as advantages of using EDE in teaching RFL:

\section{Online course format}

- use of the Stepik resource provided time needed for restructuring the educational process in the current critical situation, despite the fact that the courses were originally created as elective ones, designed to help students prepare for the control pre-examination testing;

- availability and ability to work with electronic resources from anywhere in the world;

- rapid transmission of information;

- efficient assessment of knowledge.

Disadvantages of using EDE include:

- lack of direct communication with the teacher during forced self-isolation;

- students' possible failure to understand the reasons for their mistakes;

- frequent inability to find the necessary information;

- the teacher's working time increased for preparation for classes.

\section{Video conference format}

Advantages:

- direct communication with the teacher;

- correction of errors with the teacher's help;

- activation of interaction when working with a group;

- application of various forms of training (such as inverted class, etc.)

Disadvantages:

- weakening of communication due to technical and motivational reasons [9];

- Control complicated by various reasons: technical problems, imperfect software, inexperience of users.

\section{CONCLUSION}

Thus, it can be concluded:

1. Full transition to EDE makes it possible to maintain the productivity of the educational process;

2. EDE forms must be complex or integrated, and cannot be limited to a single resource;

3. With full transition to EDE, there is a certain percentage of the decline of academic performance due to the issue of self-discipline, technical difficulties and reduced motivation caused by lack of direct communication;

4. EDE can definitely be used as a tool in teaching RFL, both partially and fully (in certain situations), but it cannot replace teaching in the classroom.

Thus, regardless of all these disadvantages, electronic distance education (EDE) is becoming a necessary tool globally, as it expands the capabilities of both teacher and student in the virtual educational space. This is especially important in the context of rapidly developing technological progress, with more and more electronic resources and their products coming into being.

\section{References}

1. Zakharova N., Yudintseva A. (2019). Online education: Prospects of development in Russia. Universal Journal of Educational Research, 7(10 B), 11-15. 
2. Nikitina G., Ternova N. (2019). Electronic teaching aids as a means of intensifying the process of foreign language teaching. Perspektivy Nauki i Obrazovania, 42(6), 435-444.

3. Dos Santos, L. M. (2020). The Discussion of Communicative Language Teaching Approach in Language Classrooms. Journal of Education and e-Learning Research, 7(2), 104-109.

4. Dyakova T., Khvorova L. (2020). Online lesson of Russian as a foreign language in the context of pedagogical activity digital transformation. Russian Language Studies, 18(2), 209-219.

5. Mello, L. (2016). Fostering postgraduate student engagement: Online resources supporting self-directed learning in a diverse cohort. Research in Learning Technology, 24, 29366.

6. Vyazovskaya V., Danilevskaya T., Trubchaninova M. (2020). Online resources in teaching Russian as a foreign language: expectations vs reality. Russian Language Studies, 18(1), 69-84.

7. Zhang., L. (2019). Development of an information-based online foreign language teaching platform with ASP.NET. International Journal of Emerging Technologies in Learning, 14(13) 117-128.

8. Krajcso Z., Frimmel U. (2017). Retrieving Online Language Learning Resources: Classification and Quality. Universal Journal of Educational Research, 5(1), 11-22.

9. Moskalenko M., Dorozhkin E., Tolstykh O. (2018). Electronic learning resources and online education technology: Issues of effectiveness evaluation. International Journal of Engineering and Technology (UAE), 7(2.13), 189-193.

10. Fisher, G., Stevenson, R., Neubert, E., Burnell, D., Kuratko, D. F. (2020). Entrepreneurial Hustle: Navigating Uncertainty and Enrolling Venture Stakeholders through Urgent and Unorthodox Action. Journal of Management Studies, 57(I5), 1002-1036.

11. Bacq S., Geoghegan W., Josefy M., Stevenson R., Williams T. A., (2020). The COVID-19 Virtual Idea Blitz: Marshaling social entrepreneurship to rapidly respond to urgent grand challenges. Business Horizons, 63(6), 705-723.

12. Costaa, C., Alvelosa, H., Teixeiraa, L. (2012). The Use of Moodle E-learning Platform: a Study in a Portuguese University. In J. Varajao, M. Cunha, P. Yetton \& R. Rijo (Eds.), Proceedings of the Conference on Enterprise Information Systems (pp. 334-343). Portugal: Procedia Technology.

13. Svetlana L., Savilova, E. V., Kokhanovskaya, E., G. Smychkova, A. A. Kropotkina, M. Ch. (2019). Motivating Bilingual Students to Study Foreign Languages: A Case Study of Learning Russian as a Foreign Language: In Ali Turkyilmaz (Ed.), Proceedings of the 2nd International Conference on Contemporary Education and Economic Development (CEED 2019) (pp.33-50), China, Beijing: Clausius Scientific Press.

14. Савилова С. Л., Кропоткина А. А., Кохановская Е. В., Смычкова Е. Г., Чай М. А. (2020). Дистанционное обучение иностранному языку в период пандемии на примере русского языка как иностранного: из опыта работы. Цифровая гуманитаристика и технологии в образовании (DНTЕ 2020): сб. материалов Всероссийской научно-практической конференции $c$ международным участием (pp. 112-123), Moscow : Moscow State Psychological and Pedagogical University. 
15. Putri R., Purwanto A., Pramono R. (2020). Impact of the COVID-19 pandemic on online home learning: An explorative study of primary schools in Indonesia. International Journal of Advanced Science and Technology, 29(5), 4809-4818.

16. Nicolai J. F. (2020). Behavioral Strategy and the COVID-19 Disruption. Journal of Management, 46(8), 1322-1329. 